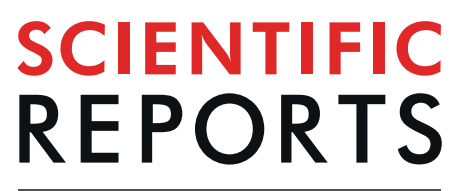

natureresearch

Check for updates

\title{
The Southern Ocean with the largest uptake of anthropogenic nitrogen into the ocean interior
}

\begin{abstract}
Xianliang L. Pan ${ }^{1 凶}$, Bofeng F. Li ${ }^{2}$ Yutaka W. Watanabe ${ }^{2}$
The oceanic external nitrogen $\left(\mathrm{N}_{\mathrm{ex}}\right)$ deposition to the global ocean is expected to rise significantly owing to human activities. The Southern Ocean (SO) is an important pathway, which brings external influences into the ocean interior. It touches the borders of several developing countries that emit a large amount of anthropogenic nitrogen. To comprehend the dynamics of $\mathrm{N}_{\mathrm{ex}}$ in the SO, we developed a new method to assess the change in the oceanic uptake of $N_{e x}\left(\Delta N_{e x}\right)$ in the entire SO. We obtained the spatiotemporal distribution of $\Delta \mathrm{N}_{\mathrm{ex}}$ in the SO by applying this method to a high-resolution grid data constructed using ship-based observations. During the 1990 s to the 2010 s, $\mathrm{N}_{\mathrm{ex}}$ increased significantly by $67 \pm 1 \mathrm{Tg}-\mathrm{N}_{\text {year }}{ }^{-1}$ in the SO. By comparing this value with the rate of $\mathrm{N}_{\mathrm{ex}}$ deposition to the ocean, the SO has received $\sim 70 \%$ of $\mathrm{N}_{\text {ex }}$ deposition to the global ocean, indicating that it is the largest uptake region of anthropogenic nitrogen into the ocean interior.
\end{abstract}

The reactive nitrogen $\left(\mathrm{N}_{\mathrm{r}}\right.$, i.e. $\mathrm{NO}_{\mathrm{x}}, \mathrm{NH}_{\mathrm{y}}$ and dissolved organic nitrogen) input to the open ocean has increased significantly since 1860 , especially in the last two decades ${ }^{1}$. Such consistent increase in the reactive nitrogen input could lead to changes in the ocean nitrogen and carbon cycles apart from affecting the marine biological productivity. Anthropogenic nitrogen released by human activities such as industrial nitrogen fixation and combustion of fossil fuel has contributed the most towards this increase. Nearly $70 \%$ of oceanic external nitrogen $\left(\mathrm{N}_{\mathrm{ex}}\right)$, which is defined as the input of fluvial and atmospheric $\mathrm{N}_{\mathrm{r}}$ in this study, is anthropogenic $\mathrm{N}_{\mathrm{r}}{ }^{2}$. Considering that the turnover time of natural $\mathrm{N}_{\mathrm{r}}$ in the ocean is approximately 3,000 years ${ }^{3,4}$, the change in $\mathrm{N}_{\mathrm{ex}}\left(\Delta \mathrm{N}_{\mathrm{ex}}\right)$ on the decadal timescale can closely reflect the change in the anthropogenic uptake in the ocean. The distribution of $\Delta \mathrm{N}_{\mathrm{ex}}$ in the surface ocean has been reported by several studies ${ }^{1,5,6}$. However, the spatiotemporal distribution of $\Delta \mathrm{N}_{\mathrm{ex}}$ in the ocean interior is yet to be revealed clearly; consequently, we lack the comprehension of the amount and storage of anthropogenic nitrogen received by the ocean as well as the variation in the oceanic uptake of anthropogenic nitrogen with time.

The Southern Ocean (SO, south of $30^{\circ} \mathrm{S}$ ) covers approximately $30 \%$ of the global ocean surface area, and it is an important pathway that drives external influences such as anthropogenic impact into the global ocean interior owing to the strong movement of water masses (e.g. meridional overturning circulation) ${ }^{7}$. The SO is also very susceptible to anthropogenic materials because much of the sea surface water flowing into the SO touches the borders of several developing countries such as China, India, and South-East Asian countries. Therefore, clarifying the ocean dynamics of $\mathrm{N}_{\mathrm{ex}}$ in the $\mathrm{SO}$ is crucial for gaining a deep understanding of the human impact on the ocean.

However, there are two challenges in exploring the presence of $\mathrm{N}_{\mathrm{ex}}$ in the SO. One is the difficulty in acquiring ocean observations owing to the severe environmental condition of the SO. Ship-based observational data of the SO are considerably deficient compared with those of other oceans in the Northern Hemisphere. Recent studies on climate change in the SO have mainly focused on multiple repeated ship-based observations along the same lines every decade; the data collected is sparse owing to the difficulty in collecting data from the entire $\mathrm{SO}^{8,9}$. The other challenge is difficulty in separating $\mathrm{N}_{\mathrm{ex}}$ from the internal nitrogen (recycled nitrogen, $\mathrm{N}_{\text {in }}$ ). Kim et al. (2014) reported the impact of anthropogenic nitrogen on the western North Pacific using $\mathrm{N}^{*}$ and the water mass age $\mathrm{e}^{6}$. Their approach could not remove the effect of nitrogen fixation and denitrification; consequently, it was difficult to estimate the anthropogenic nitrogen in the ocean accurately and apply it to the global ocean.

Recently, a new method capable of estimating the change in anthropogenic $\mathrm{CO}_{2}$ impact on the ocean interior across decadal time intervals using parameterization techniques was proposed ${ }^{10}$, which makes it possible to

${ }^{1}$ Graduate School of Environmental Science, Hokkaido University, Sapporo, Japan. ${ }^{2}$ Faculty of Environmental Earth Science, Hokkaido University, Sapporo, Japan. ${ }^{\bowtie}$ e-mail: panxianliang@ees.hokudai.ac.jp 
overcome the two abovementioned difficulties related to the SO. Here, we have extended this method to $\mathrm{N}_{\mathrm{ex}}$ and attempted to obtain the spatiotemporal distribution of $\Delta \mathrm{N}_{\mathrm{ex}}$ in the entire $\mathrm{SO}$.

\section{Results and Discussion}

Parameterization of reactive nitrogen. We use nitrate $(\mathrm{N})$ to represent $\mathrm{N}_{\mathrm{r}}$ because nitrate accounts for more than $90 \%$ of $\mathrm{N}_{\mathrm{r}}$ and it is the most stable dissolved form of nitrogen in the interior ocean (where most of ammonium and organic nitrogen are already conversed into $\mathrm{N}$ through nitrification or remineralization) ${ }^{3}$. The parameterization technique allows us to reconstruct the nitrate concentration spatiotemporally in the SO by using other hydrographic properties ${ }^{11}$. We used the hydrographic data for dissolved oxygen $\left(\mathrm{DO}\right.$ or $\left.\mathrm{O}_{2}\right)$, water temperature $(\mathrm{T})$, salinity $(\mathrm{S})$, and pressure $(\mathrm{Pr})$ along with the observed $\mathrm{N}\left(\mathrm{N}_{\mathrm{obs}}\right)$ to perform the parameterization of $\mathrm{N}$ in the SO. All the data we used were sourced from Global Ocean Data Analysis Project version 2 (GLODAP v2), Climate and Ocean: Variability, Predictability and Change (CLIVAR), and Carbon Hydrographic Data Office (CCHDO) (https://cchdo.ucsd.edu/; Table S1 and Fig. S1(a) $)^{12,13}$. By giving several data constraints in obtaining an optimal parameterization (Table S2), we obtained the predicted concentration of $\mathrm{N}\left(\mathrm{N}_{\mathrm{p}}\right)$ in the SO, as follows:

$$
\mathrm{N}_{\mathrm{p}}=394.3-9.208 \times 10^{-2} \cdot \mathrm{DO}-1.534 \cdot \mathrm{T}-9.862 \cdot \mathrm{S}+2.029 \times 10^{-4} \cdot \mathrm{Pr}
$$

(Number of data points $(n)=65,257$; Coefficient of determination $\left(R^{2}\right)=0.97$; Root-mean-square error $\left.(\mathrm{RMSE})=0.80 \mu \mathrm{mol} \mathrm{kg}{ }^{-1}\right)$

More details of our parameterization method are presented in Figs. S2 and S3 and Table S3. Several statistical tests and an independent dataset were used to confirm the accuracy of our parameterization method (see Supplementary Text S2 for details). Additionally, we compared the spatial distributions of $\mathrm{N}_{\mathrm{obs}}$ and $\mathrm{N}_{\mathrm{p}}$ in the $\mathrm{SO}$ of $30^{\circ} \mathrm{S}$ south at surface, $500 \mathrm{~m}, 1,500 \mathrm{~m}, 3,000 \mathrm{~m}$ and 5,000 $\mathrm{m}$ (Fig. S4); consequently, the distribution of $\mathrm{N}_{\mathrm{p}}$ was in good agreement with that of $\mathrm{N}_{\mathrm{obs}}$, demonstrating that our parameterization has high accuracy and applicability to the reconstruction of $\mathrm{N}$ in the entire $\mathrm{SO}$.

\section{Oceanic uptake of external nitrogen}

Separation of $\mathbf{N}_{\text {ex }}$ from oceanic $\mathbf{N}$. $\mathrm{N}_{\text {obs }}$ comprises an internal term $\left(\mathrm{N}_{\text {in }}\right)$ and an external term $\left(\mathrm{N}_{\mathrm{ex}}\right)$ because the modern hydrographic data we used were already influenced by changes in the external matter. Heretofore, the separation of these two terms of $\mathrm{N}_{\text {obs }}$ was challenging. A method to estimate the variation in the external term of the observed ocean carbon species across different arbitrary years was proposed recently ${ }^{10}$. This method could be extended to distinguish $\mathrm{N}_{\mathrm{in}}$ and $\mathrm{N}_{\mathrm{ex}}$ (see Supplementary Text S4). We assumed that $\mathrm{N}_{\mathrm{ex}}$ contained in $\mathrm{N}_{\mathrm{p}}$ is the average $\mathrm{N}_{\mathrm{ex}}$ between 2000 and $2016\left(\mathrm{~N}_{\mathrm{ex} \mathrm{2008}}\right)$ and it remains constant with time due to the use of cruise data from 2000 to 2016 for constructing the parameterization of $\mathrm{N}_{\mathrm{p}}$. We can estimate the variation in $\mathrm{N}_{\mathrm{in}}$ by considering the difference in $\mathrm{N}_{\mathrm{p}}$ across different years $\left(\Delta \mathrm{N}_{\mathrm{p}}\right)$ due to the difference in $\mathrm{N}_{\mathrm{ex}}$ as zero. The variation in $\mathrm{N}_{\mathrm{ex}}\left(\Delta \mathrm{N}_{\mathrm{ex}}\right)$ can be obtained by subtracting $\Delta \mathrm{N}_{\mathrm{p}}$ from the variation in the observed $\mathrm{N}\left(\Delta \mathrm{N}_{\mathrm{obs}}\right)$ (Fig. S6; Eqs. (S2-S5)). Here, $\mathrm{N}_{\text {in }}$ includes the nitrate originating from the processes associated with DO, T, $\mathrm{S}$, and $\mathrm{Pr}$ in the ocean, such as biological nitrogen fixation and remineralization; $\mathrm{N}_{\mathrm{ex}}$ represents only the effects of atmospheric deposition and riverine nitrogen.

Through this method, we noticed that we could estimate $\Delta \mathrm{N}_{\mathrm{ex}}$ for a particular place by using $\Delta \mathrm{N}_{\mathrm{p}}$ along with the data for $\Delta \mathrm{N}_{\mathrm{obs}}$ of that place for different years (Fig. S6(b)). In order to draw the cross sections of $\Delta \mathrm{N}_{\mathrm{ex}}$ in the SO, we selected three repeated observations from the 1990s to the 2010s along the lines SR03, I08, and A12 as the representative data for the Pacific, Indian, and Atlantic basins (Fig. S7). Considering the uncertainty of the $\mathrm{N}_{\mathrm{p}}$ parameterization (RMSE $=0.80 \mu \mathrm{mol} \mathrm{kg}-1$ ) and the propagation of uncertainty from the calculation (Eq. (S5)), $\Delta \mathrm{N}_{\mathrm{ex}}$ has an uncertainty of $1.13 \mu \mathrm{mol} \mathrm{kg}{ }^{-1}$, which means that $\Delta \mathrm{N}_{\mathrm{ex}}$ larger than this value must be significant. We estimated the meridional distributions of total water column inventory of $\Delta \mathrm{N}_{\mathrm{ex}}$ along each section (Fig. 1) by integrating $\Delta \mathrm{N}_{\mathrm{ex}}$ from the surface to the sea floor. Both SR03 and A12 have high water column inventories of $\Delta \mathrm{N}_{\mathrm{ex}}$ between the Antarctic Polar Front and the Subantarctic Front $\left(50^{\circ} \mathrm{S}\right.$ to $\left.55^{\circ} \mathrm{S}\right)$, and both I08 and $\mathrm{A} 12$ near the Antarctic continent $\left(60^{\circ} \mathrm{S}\right)$ also show high water column inventories of $\Delta \mathrm{N}_{\mathrm{ex}}$. Considering the low primary production on the surface of the $\mathrm{SO}^{14}$, the $\mathrm{N}_{\mathrm{ex}}$ deposited on the surface must mainly enter the ocean interior through the formation of intermediate and deep waters and the penetration of surface water mass in the $\mathrm{SO}^{15}$. The Antarctic Circumpolar Current has become more active due to the strengthening of the westerly winds caused by the Southern Annular Mode, which has been increasing in the past two decades ${ }^{16}$. This phenomenon has strengthened the vertical exchanges of water masses in the SO, which supports the inference that there were remarkable increases in $\mathrm{N}_{\mathrm{ex}}$ during the past 20 years in the Antarctic Intermediate Water and the Antarctic Bottom Water (Fig. S7).

Spatiotemporal distributions of $\Delta N_{p}$ and $\Delta N_{e x}$ over the Southern Ocean. Here, we used the same method as the previous sub-section to understand the distributions of $\Delta \mathrm{N}_{\mathrm{p}}$ (variation in internal $\mathrm{N}$ ) and $\Delta \mathrm{N}_{\mathrm{ex}}$ over the entire SO. Considering the lack of observational data in the SO and the necessity for repeated observational data for the same location, we selected the observational data corresponding to the period 1990-1999 to represent the 1990s, 2000-2009 to represent the 2000s, and 2010-2017 to represent the 2010s. The data of each period were interpolated onto a common grid (see Supplementary Text S3). We used a grid with horizontal resolution of $1^{\circ} \times 1^{\circ}$, and 43 vertical layers with 50 - $\mathrm{m}$ thickness from the surface to $500 \mathrm{~m}, 100$ - $\mathrm{m}$ thickness from $600 \mathrm{~m}$ to $1,500 \mathrm{~m}$, and 200-m thickness from $1,700 \mathrm{~m}$ to the sea floor.

Seasonal differences between different cruises may affect our estimation. Owing to the severe environment of the SO, most of our observed data were collected in the warm period. In order to verify whether there was a significant difference between the data for cold period (for convenience, we call it wintertime) and warm period (for convenience, we call it summertime), we used the data of wintertime (April to October) and summertime 

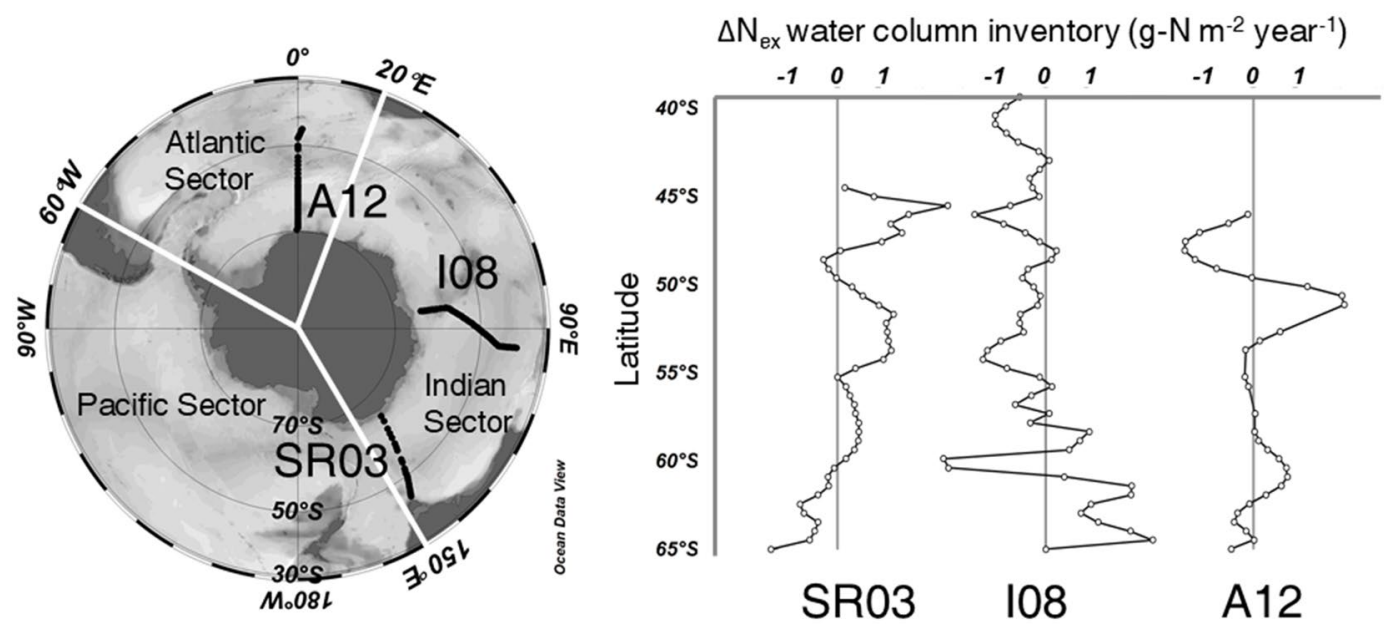

Figure 1. Meridional distributions of water column inventory of $\Delta \mathrm{N}_{\mathrm{ex}}$ along three lines in the SO. SR03 (left, from 1991 to 2011), I08 (middle, from 1994 to 2016), and A12 (right, from 1992 to 2014), as the annual rate of water column inventory of $\Delta \mathrm{N}_{\mathrm{ex}}$ during the period from the $1990 \mathrm{~s}$ to the $2010 \mathrm{~s}$, in units of $\mathrm{g}-\mathrm{N} \mathrm{m}^{-2}$ year $^{-1}$. The inventories were determined by integrating from the surface to the sea floor. White lines separate the three sectors of the SO (the Pacific sector, the Indian sector, and the Atlantic sector). This figure was drawn using Ocean Data View ${ }^{31}$.

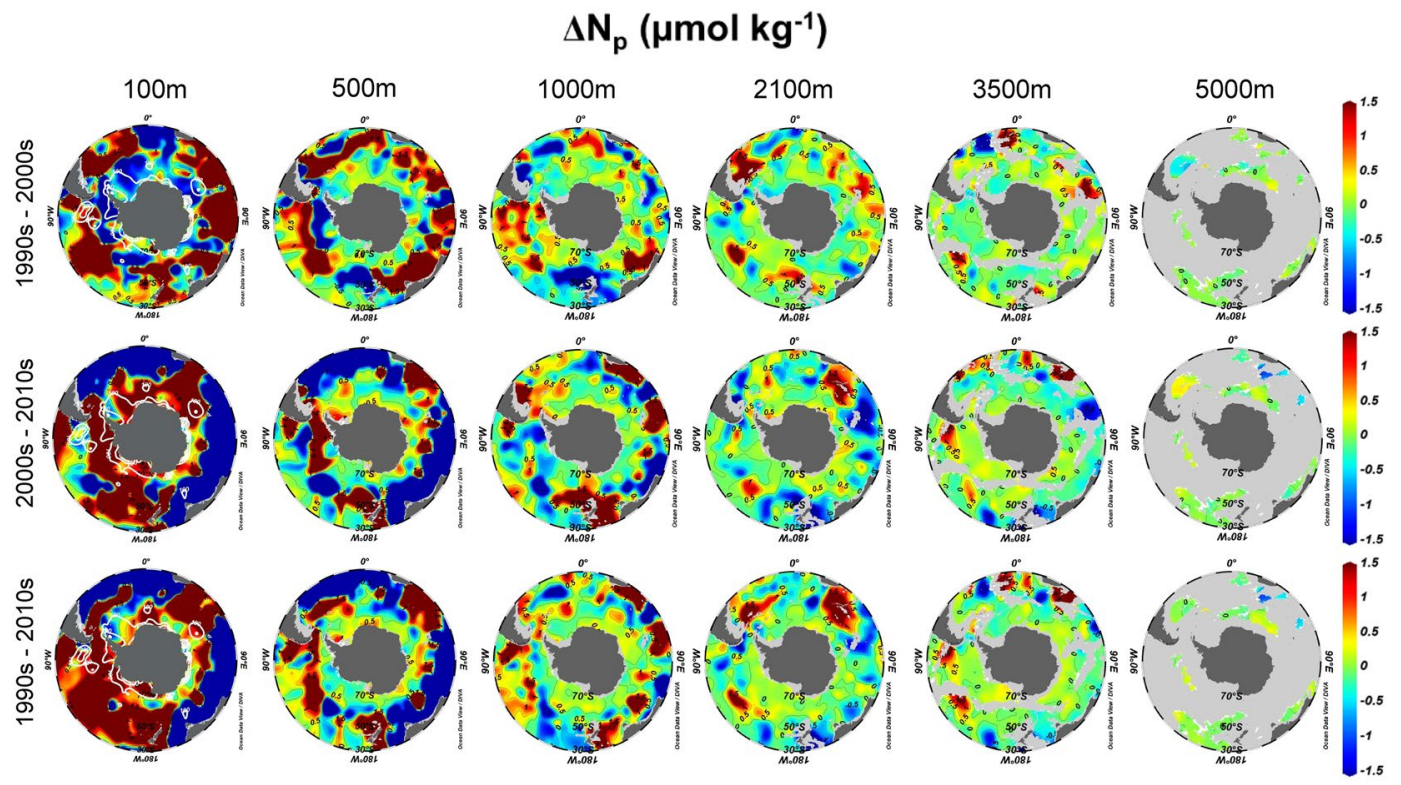

Figure 2. Horizontal distributions of the decadal change in $\mathrm{N}_{\mathrm{p}}$ in the SO. Shown were $\Delta \mathrm{N}_{\mathrm{p}}$ from the 1990s to the 2000s (top row), 2000s to 2010s (middle row), and 1990s to 2010s (bottom row) at different depths, in units of $\mu \mathrm{mol} \mathrm{kg}{ }^{-1}$. Grey areas show the sea floors. White contour lines indicate the regions where the mixed layer is deeper than $100 \mathrm{~m}$. This figure was drawn using Ocean Data View ${ }^{31}$.

(January to March) and calculated the average $\mathrm{N}_{\mathrm{obs}}$ and $\mathrm{N}_{\mathrm{p}}$ at each depth for these two durations (Fig. S8). We found that above the depth of $500 \mathrm{~m}$ the differences of both $\mathrm{N}_{\mathrm{obs}}$ and $\mathrm{N}_{\mathrm{p}}$ between the two seasons were $\sim 3 \mu \mathrm{mol}$ $\mathrm{kg}^{-1}$ as maximum; the corresponding differences at the depth of around $200 \mathrm{~m}$ became $\sim 0.80 \mu \mathrm{mol} \mathrm{kg}^{-1}$, which was equal to the RMSE of our parameterization. These two periods did not show an obvious difference below the depth of $500 \mathrm{~m}$. Thus, we concluded that the seasonal difference in the observational data does not significantly affect the spatiotemporal distributions of $\Delta \mathrm{N}_{\mathrm{ex}}$ along with the total water column inventory.

The spatiotemporal distributions of $\Delta \mathrm{N}_{\mathrm{p}}$ and $\Delta \mathrm{N}_{\mathrm{ex}}$ are shown in Figs. 2 and 3(a), respectively. The spatiotemporal distribution of $\Delta \mathrm{N}_{\mathrm{p}}$ (Fig. 2) showed a large variation in the upper 1,000 m water column and it revolved around the Antarctic continent along with the Antarctic Circumpolar Current in the different time periods. This phenomenon may be due to the continuing enhanced nutrient-rich Circumpolar Deep Water upwelling derived from the strengthening of the Southern Hemisphere westerlies in recent decades ${ }^{17,18}$. Furthermore, $\Delta \mathrm{N}_{\mathrm{p}}$ became 


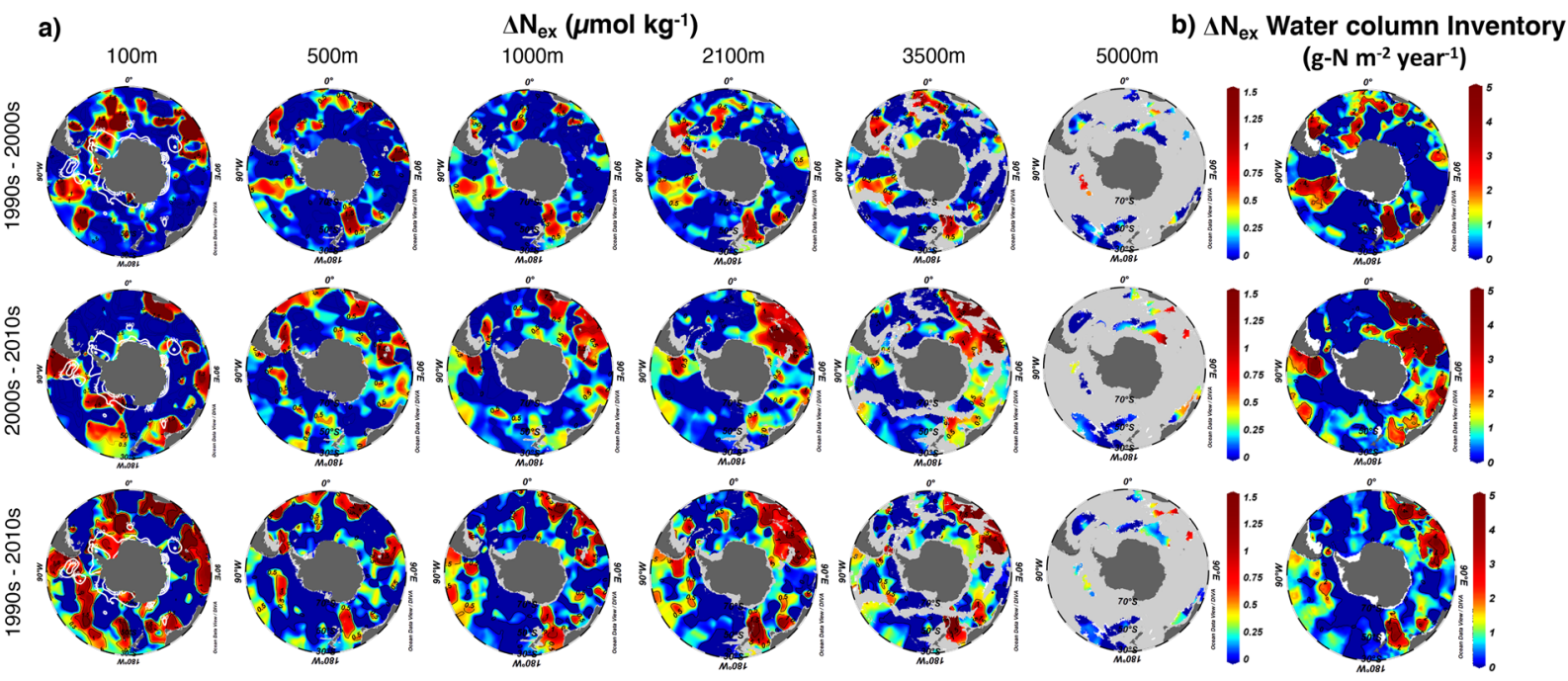

Figure 3. Horizontal distributions of the decadal change in $\mathrm{N}_{\mathrm{ex}}$ in the SO. Shown along with the annual rate of change in the SO south of $30^{\circ} \mathrm{S}$. (a) The decadal change in $\mathrm{N}_{\mathrm{ex}}$ during the period from the 1990 s to the 2000s (top row), 2000s to 2010s (middle row), and 1990s to 2010s (bottom row) at different depths. Scale was fixed from 0 to $1.5 \mu \mathrm{mol} \mathrm{kg}{ }^{-1}$ to emphasize the increase in $\mathrm{N}_{\mathrm{ex}}$. Grey areas show the sea floors. (b) Total water column inventories of $\Delta \mathrm{N}_{\mathrm{ex}}$ as the annual rate of change in $\mathrm{N}_{\mathrm{ex}}$ over the same periods as in (a), in units of g-N $\mathrm{m}^{-2}$ year ${ }^{-1}$. Inventories were determined by integrating $\Delta \mathrm{N}_{\mathrm{ex}}$ from the surface to the depth of 5,900 $\mathrm{m}$. White contour lines indicate the regions where the mixed layer is deeper than $100 \mathrm{~m}$. This figure was drawn using Ocean Data View ${ }^{31}$.

\begin{tabular}{|l|l|l|l|l|}
\hline Period & $\begin{array}{l}\text { Pacific } \\
\text { Sector }\end{array}$ & $\begin{array}{l}\text { Indian } \\
\text { Sector }\end{array}$ & $\begin{array}{l}\text { Atlantic } \\
\text { Sector }\end{array}$ & $\begin{array}{l}\text { Southern } \\
\text { Ocean }\end{array}$ \\
\hline 1990s-2000s & $25 \pm 1$ & $-4 \pm 1$ & $17 \pm 1$ & $38 \pm 2$ \\
\hline $2000 s-2010 s$ & $24 \pm 1$ & $100 \pm 2$ & $-22 \pm 1$ & $102 \pm 3$ \\
\hline $1990 s-2010 s$ & $24 \pm 1$ & $42 \pm 1$ & $0.02 \pm 0$ & $67 \pm 1$ \\
\hline
\end{tabular}

Table 1. Total water column inventory of $\Delta \mathrm{N}_{\mathrm{ex}}$ in the SO. From the surface to 5,900-m depth south of $30^{\circ} \mathrm{S}$ during the 1990s - 2010s (Tg-N year ${ }^{-1}$ ) (Pacific Sector: $150^{\circ} \mathrm{E}-60^{\circ} \mathrm{W}$; Indian Sector: $20^{\circ} \mathrm{E}-150^{\circ} \mathrm{E}$; Atlantic Sector: $60^{\circ} \mathrm{W}-20^{\circ} \mathrm{E}$ ). The uncertainty is the value of the standard error divided by the average of each sector (see Table S6 for detail).

zero gradually with the increase of depth, implying that there is almost no nature-derived variation of $\mathrm{N}$ in the deeper water column. The distribution of $\Delta \mathrm{N}_{\mathrm{p}}$ showed no obvious difference between the Pacific, the Indian and the Atlantic sector of the SO.

In Fig. 3(a), the spatial distribution of $\Delta \mathrm{N}_{\mathrm{ex}}$ in the surface layer shows a tendency to diffuse along the continental coastal area to the open ocean (e.g. west coast of South America, southwest coast of South Africa, and south of Tasmania, Australia). The data for the continental shelf were removed to eliminate the uncertainty of river input in our parameterization construction based on the assumption that the riverine $\mathrm{N}_{\mathrm{ex}}$ has little effect on the open ocean ${ }^{1}$ (see Supplementary Text S1). Jickells et al. (2017) found that approximately $75 \%$ of riverine $\mathrm{N}$ escapes beyond the shelf break and enters the open ocean, which may partly explain the significant rise in $\mathrm{N}_{\mathrm{ex}}$ in the coastal region in our study.

In terms of the temporal distribution of $\Delta \mathrm{N}_{\mathrm{ex}}$, the Indian sector has shown a remarkable growth in $\mathrm{N}_{\mathrm{ex}}$ from the surface to the abyss during the period from the 2000s to the 2010s. By analyzing the spatiotemporal distribution, the reason for this can be attributed to the increase in anthropogenic nitrogen emission in developing countries such as India, China, and Southern Africa in the past decade ${ }^{5,19,20}$. According to the evaluation of the global meridional overturning circulation, the upwelling water in the surface North Pacific Ocean passes through the Strait of Malacca and reaches the northern Indian Ocean. Then, it goes south and flows into the Southern Ocean ${ }^{7}$. Meanwhile, the surface anthropogenic $\mathrm{N}$ is loaded on these waters along the coastal regions and brought to the Southern Ocean. Additionally, the enhancement of the Southern Annular Mode mentioned in the previous section can explain the increase in $\mathrm{N}_{\mathrm{ex}}$ in the ocean interior.

We also estimated the total water column inventory of $\Delta \mathrm{N}_{\mathrm{ex}}$ from the surface to the sea floor in the SO (Fig. 3(b) and Table 1). During the 1990s to the 2010s, $\mathrm{N}_{\mathrm{ex}}$ in the Pacific, Indian, and Atlantic sectors grew at the rate of $24 \pm 1,42 \pm 1$, and $0.02 \pm 0 \mathrm{Tg}-\mathrm{N}$ year $^{-1}$, respectively, and that for the entire SO grew at the rate of $67 \pm 1$ Tg-N year ${ }^{-1}$. Uncertainties were given by the standard error of gridding estimation (Table S6). The $\Delta \mathrm{N}_{\mathrm{ex}}$ in the Indian sector accounted for $63 \%$ of the increase in $\mathrm{N}_{\mathrm{ex}}$ in the SO. We also found that the Atlantic Sector, which has the most active vertical circulation in the world, did not show a high $\Delta \mathrm{N}_{\mathrm{ex}}$. This may be because of the following 
two reasons: (1) the deviation caused by the seasonal differences in the surface data (Fig. S8); (2) the inflow of the deposition of $\mathrm{N}_{\mathrm{ex}}$ from the Atlantic sector into the Indian sector due to the Antarctic Circumpolar Current, which also explains why $\Delta \mathrm{N}_{\mathrm{ex}}$ in the Indian sector is extremely high. In the Pacific Ocean, we mainly observed the accumulation of $\Delta \mathrm{N}_{\mathrm{ex}}$ in the surface layer (Fig. 3) due to the upwelling area with relatively old water age in the deep Pacific ${ }^{21}$. These results can be considered reasonable compared with the previous model predictions ${ }^{1,5}$.

In an early study ${ }^{1}$, the deposition rate of $\mathrm{N}_{\mathrm{ex}}$ to the global ocean was predicted as $67 \pm 30 \mathrm{Tg}^{\mathrm{N}} \mathrm{N}$ year ${ }^{-1}$ in the 2000s, the upper limit of which was $96 \mathrm{Tg}-\mathrm{N}$ year ${ }^{-1}$ considering the potential impact of riverine input. By comparing the deposition rate with our data, we found that the SO had received $69 \%$ of the global oceanic $\mathrm{N}_{\mathrm{ex}}$ input despite the SO covering only $29 \%$ of the global ocean surface area, which emphasizes the important role of the SO in integrating anthropogenic impacts in the global ocean.

\section{Conclusions}

We presented the spatiotemporal distributions of $\Delta \mathrm{N}_{\mathrm{p}}$ and $\Delta \mathrm{N}_{\mathrm{ex}}$ in the SO from the 1990s to the 2010s using the simple parameterization of the predicted $\mathrm{N}$ along with the observed $\mathrm{N}\left(\mathrm{R}^{2}=0.97\right.$; $\left.\mathrm{RMSE}=0.80 \mu \mathrm{mol} \mathrm{kg}^{-1}\right)$. In the Indian sector, which borders several developing countries, $\mathrm{N}_{\mathrm{ex}}$ has grown at a rate of $42 \pm 1 \mathrm{Tg}-\mathrm{N}$ year ${ }^{-1}$, accounting for approximately $63 \%$ of the overall rate of increase of the SO $\left(67 \pm 1 \mathrm{Tg}-\mathrm{N}\right.$ year $\left.{ }^{-1}\right)$. y comparing our result with the global deposition rate reported by Duce et al. ${ }^{1}$, the SO was found to receive approximately $70 \%$ of the global oceanic input of $\mathrm{N}_{\mathrm{ex}}$ despite it covering only one-third of the global ocean area. In the future, a more detailed evaluation of $\mathrm{N}$ in the $\mathrm{SO}$ can be obtained by relying largely on ship-based observations and/or applying this parameterization method to autonomous biogeochemical Argo floats and CTD sensors ${ }^{22-30}$.

Received: 15 January 2020; Accepted: 4 May 2020;

Published online: 01 June 2020

\section{References}

1. Duce, R. A. et al. Impacts of Atmospheric Anthropogenic Nitrogen on the Open. Ocean. Science 320, 893-897 (2008).

2. Gruber, N. \& Galloway, J. N. An Earth-system perspective of the global nitrogen cycle. Nature 451, 293-296 (2008).

3. Capone, D. G., Bronk, D. A., Mulholland, M. R. \& Carpenter, E. J. Nitrogen in the Marine Environment. (Elsevier, 2008).

4. Gruber, N. The Dynamics of the Marine Nitrogen Cycle and its Influence on Atmospheric $\mathrm{CO}_{2}$ Variations. in The Ocean Carbon Cycle and Climate 97-148 (Springer Netherlands), https://doi.org/10.1007/978-1-4020-2087-2_4 (2004).

5. Jickells, T. D. et al. A reevaluation of the magnitude and impacts of anthropogenic atmospheric nitrogen inputs on the ocean. Global Biogeochem. Cycles 31, 289-305 (2017).

6. Kim, I. et al. Increasing anthropogenic nitrogen in the North Pacific. Ocean. Science 346, 1102-1107 (2014).

7. Marshall, J. \& Speer, K. Closure of the meridional overturning circulation through Southern Ocean upwelling. Nat. Geosci. 5, $171-180$ (2012).

8. Woosley, R. J., Millero, F. J. \& Wanninkhof, R. Rapid anthropogenic changes in $\mathrm{CO}_{2}$ and pH in the Atlantic Ocean: $2003-2014$. Global Biogeochem. Cycles 30, 70-90 (2016).

9. Panassa, E. et al. Variability of nutrients and carbon dioxide in the Antarctic Intermediate Water between 1990 and 2014. Ocean Dyn. 68, 295-308 (2018).

10. Watanabe, Y. W., Li, B. F. \& Wakita, M. Long-Term Trends of Direct and Indirect Anthropogenic Effects on Changes in Ocean $\mathrm{pH}$. Geophys. Res. Lett. 45, 9106-9113 (2018).

11. Li, B. F., Watanabe, Y. W. \& Yamaguchi, A. Spatiotemporal distribution of seawater $\mathrm{pH}$ in the North Pacific subpolar region by using the parameterization technique. J. Geophys. Res. 121, 3435-3449 (2016).

12. Lauvset, S. K. et al. A new global interior ocean mapped climatology: The $1^{\circ} \times 1^{\circ}$ GLODAP version 2. Earth Syst. Sci. Data 8 , 325-340 (2016).

13. Olsen, A. et al. The global ocean data analysis project version 2 (GLODAPv2) - An internally consistent data product for the world ocean. Earth Syst. Sci. Data 8, 297-323 (2016).

14. Gregg, W. W., Conkright, M. E., Ginoux, P., O’Reilly, J. E. \& Casey, N. W. Ocean primary production and climate: Global decadal changes. Geophys. Res. Lett. 30 (2003).

15. Carter, L., McCave, I. N. \& Williams, M. J. M. Chapter 4 Circulation and Water Masses of the Southern Ocean: A Review. Dev. Earth Environ. Sci 8, 85-114 (2008).

16. Thompson, D. W. J. et al. Signatures of the Antarctic ozone hole in Southern Hemisphere surface climate change. Nat. Geosci. 4, 741-749 (2011).

17. Menviel, L. et al. Southern Hemisphere westerlies as a driver of the early deglacial atmospheric CO2 rise. Nat. Commun. 9, 1-12 (2018).

18. Peck, V. L., Allen, C. S., Kender, S., McClymont, E. L. \& Hodgson, D. Oceanographic variability on the West Antarctic Peninsula during the Holocene and the influence of upper circumpolar deep water. Quat. Sci. Rev. 119, 54-65 (2015).

19. Liu, X. et al. Enhanced nitrogen deposition over China. Nature 494, 459-462 (2013).

20. Oita, A. et al. Substantial nitrogen pollution embedded in international trade. Nat. Geosci. 9, 111-115 (2016).

21. Sarmiento, J. L. \& Gruber, N. Ocean Biogeochemical Dynamics. (Princeton University Press, New Jersey, 2006).

22. Olsen, A. et al. GLODAPv2.2019 - an update of GLODAPv2. Earth Syst. Sci. Data Discuss. 1-39, https://doi.org/10.5194/essd-201966 (2019).

23. de Boyer Montegut, C., Madec, G., Fischer, A. S., Lazar, A. \& Iudicone, D. Mixed layer depth over the global ocean: An examination of profile data and a profile-based climatology. J. Geophys. Res. 109 (2004)

24. Emery, W. J. Water Types and Water Masses. in Ocean circulation/Water Types and Water Masses 1556-1567 (University of Colorado, Boulder), https://doi.org/10.1016/b0-12-227090-8/00279-7 (2003).

25. Wilks, D. S. Statistical methods in the atmospheric sciences. (Academic Press,N.Y., 2011).

26. Switzer, A. C. Mapping nitrate in the global ocean using remotely sensed sea surface temperature. J. Geophys. Res. 108 (2003).

27. Orsi, Alejandro H. Whitworth \& Thomas, I. WOCE Southern Ocean. 1 (2005).

28. Ishizu, M. \& Richards, K. J. Relationship between oxygen, nitrate, and phosphate in the world ocean based on potential temperature. J. Geophys. Res. 118, 3586-3594 (2013).

29. Anderson, L. A. \& Sarmiento, J. L. Redfield ratios of remineralization determined by nutrient data analysis. Global Biogeochem. Cycles 8, 65-80 (1994).

30. Stramma, L., Schmidtko, S., Levin, L. A. \& Johnson, G. C. Ocean oxygen minima expansions and their biological impacts. Deep. Res. Part I Oceanogr. Res. Pap 57, 587-595 (2010).

31. Schkizer, R. https://odv.awi.de, (2020). 


\section{Acknowledgements}

We would like to thank the GLODAP group and all the researchers who contributed to the construction of global ocean databases. This study was partly supported by the Ministry of Education, Culture, Sports, Science and Technology, Japan (grant number KAKEN 18H04131).

\section{Author contributions}

X.L.P. and Y.W.W. provided the first idea of this paper; X.L.P. collected the data; X.L.P. and B.F.L. analyzed the data; X.L.P., B.F.L. and Y.W.W. co-wrote the paper.

\section{Competing interests}

The authors declare no competing interests.

\section{Additional information}

Supplementary information is available for this paper at https://doi.org/10.1038/s41598-020-65661-2.

Correspondence and requests for materials should be addressed to X.L.P.

Reprints and permissions information is available at www.nature.com/reprints.

Publisher's note Springer Nature remains neutral with regard to jurisdictional claims in published maps and institutional affiliations.

(c) (i) Open Access This article is licensed under a Creative Commons Attribution 4.0 International License, which permits use, sharing, adaptation, distribution and reproduction in any medium or format, as long as you give appropriate credit to the original author(s) and the source, provide a link to the Creative Commons license, and indicate if changes were made. The images or other third party material in this article are included in the article's Creative Commons license, unless indicated otherwise in a credit line to the material. If material is not included in the article's Creative Commons license and your intended use is not permitted by statutory regulation or exceeds the permitted use, you will need to obtain permission directly from the copyright holder. To view a copy of this license, visit http://creativecommons.org/licenses/by/4.0/.

(c) The Author(s) 2020 